\title{
Is the Control of Applied Digital Forces During Natural Five-digit Grasping Affected by Carpal Tunnel Syndrome?
}

\author{
Po-Tsun Chen MS, I-Ming Jou MD, PhD, Chien-Ju Lin PhD, \\ Hsiao-Feng Chieh PhD, Li-Chieh Kuo PhD, Fong-Chin Su PhD
}

Received: 15 September 2014 / Accepted: 3 February 2015/Published online: 18 February 2015

(C) The Association of Bone and Joint Surgeons (B) 2015

\begin{abstract}
Background The impaired sensory function of the hand induced by carpal tunnel syndrome (CTS) is known to
\end{abstract}

This work was supported by a grant from the National Health Research Institute in Taiwan (NHRI-EX102-10040EI) to one of the authors (F-CS).

All ICMJE Conflict of Interest Forms for authors and Clinical Orthopaedics and Related Research ${ }^{\circledR}$ editors and board members are on file with the publication and can be viewed on request.

Clinical Orthopaedics and Related Research ${ }^{\mathbb{R}}$ neither advocates nor endorses the use of any treatment, drug, or device. Readers are encouraged to always seek additional information, including FDA-approval status, of any drug or device prior to clinical use. Each author certifies that his or her institution approved the human protocol for this investigation, that all investigations were conducted in conformity with ethical principles of research, and that informed consent for participation in the study was obtained.

This work was performed at the Department of Biomedical Engineering, National Cheng Kung University, Tainan, Taiwan.

P.-T. Chen, C.-J. Lin, H.-F. Chieh, F.-C. Su ( $\square)$

Department of Biomedical Engineering, National Cheng Kung University, No. 1, University Road, Tainan City 701, Taiwan

e-mail: fcsu@mail.ncku.edu.tw

I.-M. Jou

Department of Orthopedics, National Cheng Kung University,

Tainan, Taiwan

C.-J. Lin, F.-C. Su

Musculoskeletal Research Center, National Cheng Kung

University, Tainan, Taiwan

L.-C. Kuo

Department of Occupational Therapy, National Cheng Kung University, Tainan, Taiwan

F.-C. Su

Medical Device Innovation Center, National Cheng Kung

University, Tainan, Taiwan disturb dexterous manipulations. However, force control during daily grasping configuration among the five digits has not been a prominent focus of study. Because grasping is so important to normal function and use of a hand, it is important to understand how sensory changes in CTS affect the digit force of natural grasp.

Questions/purposes We therefore examined the altered patterns of digit forces applied during natural five-digit grasping in patients with CTS and compared them with those seen in control subjects without CTS. We hypothesized that the patients with CTS will grasp by applying larger forces with lowered pair correlations and more force variability of the involved digits than the control subjects. Specifically, we asked: (1) Is there a difference between patients with CTS and control subjects in applied force by digits during lift-hold-lower task? (2) Is there a difference in force correlation coefficient of the digit pairs? (3) Are there force variability differences during the holding phase?

Methods We evaluated 15 female patients with CTS and 15 control subjects matched for age, gender, and hand dominance. The applied radial forces $\left(\mathrm{F}_{\mathrm{r}}\right)$ of the five digits were recorded by respective force transducers on a cylinder simulator during the lift-hold-lower task with natural grasping. The movement phases of the task were determined by a video-based motion capture system.

Results The applied forces of the thumb in patients with CTS $(7 \pm 0.8 \mathrm{~N}$; 95\% CI, 7.2-7.4 N) versus control subjects $(5 \pm 0.8 \mathrm{~N} ; 95 \% \mathrm{CI}, 5.1-5.3 \mathrm{~N})$ and the index finger in patients with CTS $(3 \pm 0.3 \mathrm{~N} ; 95 \% \mathrm{CI}, 3.2-3.3 \mathrm{~N})$ versus control subjects $(2 \pm 0.3 \mathrm{~N} ; 95 \% \mathrm{CI}, 2.2-2.3 \mathrm{~N})$ observed throughout most of the task were larger in the CTS group ( $p$ ranges $0.035-0.050$ for thumb and 0.016-0.050 for index finger). In addition, the applied force of the middle finger in patients with CTS $(1 \pm 0.1 \mathrm{~N} ; 95 \%$ 
CI, 1.3-1.4 N) versus the control subjects ( $2 \pm 0.2 \mathrm{~N}$; $95 \%$ CI, 1.9-2.0 N) during the lowering phase was larger in CTS group ( $\mathrm{p}$ ranges 0.039-0.050). The force correlations of the thumb-middle finger observed during the lowering phase in the patients with CTS $(0.8 \pm 0.2 ; 95 \%$ CI, $0.6-0.9)$ versus the control subjects $(0.9 \pm 0.1 ; 95 \% \mathrm{CI}$, $0.8-1.0 ; p=0.04)$ were weaker in the CTS group. The thumb-little finger during holding in the patients with CTS $(0.5 \pm 0.2 ; 95 \% \mathrm{CI}, 0.3-0.7)$ versus the control subjects $(0.8 \pm 0.2 ; 95 \% \mathrm{CI}, 0.6-0.9 ; \mathrm{p}=0.02)$, and the lowering phase in the patients with CTS $(0.6 \pm 0.2 ; 95 \% \mathrm{CI}$, $0.3-0.8)$ versus the control subjects $(0.9 \pm 0.1 ; 95 \% \mathrm{CI}$, $0.8-1.0 ; \mathrm{p}=0.01)$ also were weaker. The force variabilities of patients with CTS were greater in the CTS group than in the control subjects: in the thumb $([0.26 \pm 0.11 \mathrm{~N}, \quad 95 \% \quad \mathrm{CI}, \quad 0.20-0.32 \mathrm{~N}] \quad$ versus $[0.19 \pm 0.06 \mathrm{~N} ; 95 \% \mathrm{CI}, 0.16-0.22 \mathrm{~N}], \mathrm{p}=0.03)$; index finger $([0.09 \pm 0.07 \mathrm{~N} ; 95 \% \mathrm{CI}, \quad 0.05-0.13 \mathrm{~N}]$ versus $[0.05 \pm 0.03 \mathrm{~N} ; 95 \% \mathrm{CI}, 0.04-0.07 \mathrm{~N}], \mathrm{p}=0.03$ ); middle finger $([0.06 \pm 0.04 \mathrm{~N} ; 95 \% \mathrm{CI}, \quad 0.04-0.08 \mathrm{~N}]$ versus $[0.03 \pm 0.01 \mathrm{~N} ; 95 \% \mathrm{CI}, 0.02-0.04 \mathrm{~N}], \mathrm{p}=0.02$ ), and ring finger $([0.04 \pm 0.03 \mathrm{~N}$; 95\% CI, $0.20-0.06 \mathrm{~N}]$ versus $[0.02 \pm 0.01 \mathrm{~N} ; 95 \% \mathrm{CI}, 0.02-0.02 \mathrm{~N}], \mathrm{p}=0.01$ ).

Conclusions Patients with CTS grasped with greater digit force associated with weaker correlation and higher variability on specific digits in different task demands. These altered patterns in daily grasping may lead to secondary problems, which will need to be assessed in future studies with this model to see if they are reversible in patients undergoing carpal tunnel release.

Clinical Relevance The current results helped to identify altered patterns of grasping force during simulated daily function in patients with CTS and to provide the clinician with potential information that might help guide the rehabilitation of grasp in these patients.

\section{Introduction}

The hand receives sensory stimuli and performs motor commands [40] that are integrated in various functional manipulations required for daily tasks. Impairments to the sensory functions of the hand will cause disturbances to its fine motor performance. For instance, mechanical entrapment of the median nerve at the wrist region, which is known as carpal tunnel syndrome (CTS), results in numbness, pain, and weakness of the muscles innervated by the median nerve $[6,41]$. CTS is more common among women than men, and can be caused by repeated or highforce manual tasks, especially from vocational exposure $[22,37]$. As a result of symptoms caused by nerve abnormalities, patients with CTS face difficulties in various hand manipulations needed to perform daily activities, especially those requiring precision grasping [28].

Although clinical evaluations can quantitatively provide general indications regarding functional performance of the hand, the ability of fine force control may be missed by conventional assessments [2]. During the last decade, numerous devices have been used to record the forces applied by the digits during various grasp configurations [1, 21, 29, 39, 43, 45]. Studies show that patients with CTS exhibit diminished efficiency when pinching objects, implying that the affected digits are unable to accurately adjust the forces applied in response to the given external load [21, 29, 39]. As for five-digit grasping, several studies also examined the altered controls of grasping force with respect to grasping objects with different weights [45], changed center of masses [43], and various textures [1]. These studies indicated that patients with CTS grasped with excessive forces and showed an inability to discriminate weight accurately, performed less modulation of force despite changes in the center of mass, and poorly adjusted the forces applied across various textures. The force of each digit was coordinated with the forces from the other four digits and also adjusted to achieve the requirements of the task, such as the observed different patterns between vertical lifting and rotating a cup [8]. As a result, the altered coordination among digits or the compensatory role of each digit in patients with CTS should be addressed, rather than the overall grip force.

Force variability has been used to quantify the stability control of digit force, thus serving as an indicator of precision performance [7, 27]. Greater variability of digit force was observed in men compared with women [14], in the nondominant hand compared with the dominant [13], and in the elderly (60-69 years) compared with the young (20-29 years) [38]. However, few studies have examined how abnormal sensory functions affect force variability $[9,27]$, especially during five-digit grasping [45]. The synergies among the various roles of the fingers, which are described by the force relationships among thumb-finger pairs $[8,24,36]$, may provide insights into the coordination that occurs among the involved and intact digits of patients with CTS. In addition to the altered patterns of grasping force in patients with CTS, the patterns of force applied also depend on the contact positions of the digits during grasping, especially the thumb $[8,21,25,43,45]$. To assess how the impairments resulting from CTS affect daily grasping, the natural grasping configuration of patients should be considered in an experimental setting $[11,30]$.

The aim of our study therefore was to compare the control characteristics of digit forces during five-digit cylindrical grasping by patients with CTS and a group of control subjects without CTS. We hypothesized that the patients with CTS would grasp by applying larger forces 
with lowered pair correlations and more force variability of the involved digits than the control subjects. Specifically, we asked: (1) Is there a difference between patients with CTS and control subjects in applied force among the digits during lift-hold-lower task? (2) Is there a difference in force correlation coefficients of the digits? (3) Are there force variability differences during the holding phase?

\section{Patients and Methods}

\section{Participants}

To eliminate the effects of age, gender, and hand dominance on the control of digit forces [9], right-handed female subjects between the ages of 35 and 74 years were recruited and their right hands were evaluated for both groups. Fifteen female patients, who had a diagnosis of CTS in the right hand, participated in this study. The patients who had a diagnosis of idiopathic CTS of the right hand who met the inclusion criteria, which included impaired sensory and intact motor functions of the median nerve by nerve conduction velocity examination, female gender, and right hand dominance, were considered for inclusion in the study. Patients were excluded if they could not perform the testing task correctly, such as failure to grasp safely or slip occurred owing to the severely impaired sensation. We selected 15 eligible patients to participate in this study and completed the experiments.

Patients received nerve conduction examination to confirm that they had involvement of the sensory function of the median nerve only and to exclude those whose ulnar nerve and motor function of the median motor nerve were affected (Table 1). Fifteen healthy age-matched females were recruited from the community as the control group. Participants were excluded if they had a history of stroke, diabetes, cervical radiculopathy, other sensory disorders, or musculoskeletal disorders of the right wrist and hand. Participants were informed of the purpose and procedures of this study and signed consent forms approved by the institutional review board.

\section{Instruments}

The sensory and motor nerve conduction examinations in patients were performed by using Medelec Synergy ${ }^{\mathrm{TM}} \mathrm{N}-$ EP EMG apparatus (Oxford Instruments Medical, Inc, Abingdon, UK). A custom cylindrical simulator was designed with five force transducers (Nano-25 and Nano-17s; ATI Industrial Automation, Apex, NC, USA) to record the applied digit forces with a sampling rate of $800 \mathrm{~Hz}$ (Fig. 1). One transducer (Nano-25) was set for the thumb and the other four (Nano-17) were for the index, middle, ring, and little fingers. The force data recorded by the transducers were transmitted through a 16-bit A/D converter (i430; GW Instruments, Charlestown, MA, USA) and stored in a computer. Each transducer was covered with an aluminum saddle-like cap with a curved convex surface, with a 33-mm radius of curvature to form the outer circumference of the cylinder. The positions of the force transducers could be adjusted according to each participant's grasping configuration. The mapping matrix from voltage to Newton was obtained according to the product specification from ATI. Before this study, we checked the accuracy of these sensors in our laboratory by a series of standard weights within the level of tolerance. Before beginning every experiment, the baseline output voltage was mapped to zero by subtracting the default voltage in each channel. The digit force applied on the transducer in the normal direction was represented by the radial force $\left(\mathrm{F}_{\mathrm{r}}\right)$ and analyzed in the current study. A video-based motion capture system with eight cameras (Eagle System, EGL-500RT; Motion Analysis Corporation, Santa Rosa, CA, USA) was used to record the dynamic position of the simulator during testing for determination of task phases, with a sampling rate of $100 \mathrm{~Hz}$. The coordinate system of the simulator was defined by three reflective markers attached to the top plate: the first and second markers were aligned with the force transducer for the thumb and index finger, respectively, and the third marker was on the intersection of the circumference and line perpendicular to the line between the first and second markers.

\section{Nerve Conduction Examination}

The temperature of the laboratory and the skin of the upper extremity of the patient was maintained at $23^{\circ}$ to $26^{\circ}$ and $32{ }^{\circ} \mathrm{C}$, respectively. Three different sites, including the palm, wrist, and elbow, were selected for stimulating the median nerve with the surface recording ring electrodes on the index finger [34]. The amplitude of the sensory nerve action potential during stimulation at the wrist, the peak distal latency of sensory nerve action potential recorded during stimulation at the wrist, and conduction velocity in the segment from the wrist to the palm were used to represent the response of the sensory nerve.

\section{Experimental Procedure}

The participants were first asked to clean their digit pads with alcohol swabs. The resting position of the subject was to sit upright on a height-adjustable chair with the upper arms against the side of the body and forearms resting on 
Table 1. Demographic data of nerve conduction examination on median and ulnar nerve in patients with CTS

\begin{tabular}{|c|c|c|c|c|c|c|}
\hline $\begin{array}{l}\text { Patient } \\
\text { number }\end{array}$ & Occupation & Age (years) & Nerve & $\begin{array}{l}\text { Amplitude }(\mathrm{V} \text { for } \\
\text { sensory, } \mu \mathrm{V} \text { for } \\
\text { motor) }\end{array}$ & $\begin{array}{l}\text { Velocity } \\
\text { (m/second) }\end{array}$ & $\begin{array}{l}\text { Latency } \\
(\mathrm{ms})\end{array}$ \\
\hline \multirow[t]{3}{*}{1} & \multirow[t]{3}{*}{ Housewife } & \multirow[t]{3}{*}{41} & Median sensory & 4.2 & 37.7 & 3.7 \\
\hline & & & Median motor & 6.8 & 47.4 & 4.2 \\
\hline & & & Ulnar sensory & 14 & 45.4 & 2.3 \\
\hline \multirow[t]{3}{*}{2} & \multirow[t]{3}{*}{ Accountant } & \multirow[t]{3}{*}{35} & Median sensory & 8 & 32 & 4.5 \\
\hline & & & Median motor & 6.2 & 63 & 3.4 \\
\hline & & & Ulnar sensory & 19 & 62 & 2.0 \\
\hline \multirow[t]{3}{*}{3} & \multirow[t]{3}{*}{ Porter } & \multirow[t]{3}{*}{60} & Median sensory & 35 & 34 & 2.9 \\
\hline & & & Median motor & 4 & 54 & 3.6 \\
\hline & & & Ulnar sensory & 18 & 48 & 2.4 \\
\hline \multirow[t]{3}{*}{4} & \multirow[t]{3}{*}{ Teacher } & \multirow[t]{3}{*}{53} & Median sensory & 14 & 42 & 3.3 \\
\hline & & & Median motor & 6.4 & 62 & 4.1 \\
\hline & & & Ulnar sensory & 17 & 53 & 2.0 \\
\hline \multirow[t]{3}{*}{5} & \multirow[t]{3}{*}{ Cleaner } & \multirow[t]{3}{*}{39} & Median sensory & 14 & 36 & 3.7 \\
\hline & & & Median motor & 7.4 & 55 & 3.4 \\
\hline & & & Ulnar sensory & 14 & 51 & 2.4 \\
\hline \multirow[t]{3}{*}{6} & \multirow[t]{3}{*}{ Cook } & \multirow[t]{3}{*}{55} & Median sensory & 9 & 23 & 5.9 \\
\hline & & & Median motor & 4.9 & 57 & 3.6 \\
\hline & & & Ulnar sensory & 13 & 49 & 2.2 \\
\hline \multirow[t]{3}{*}{7} & \multirow[t]{3}{*}{ Packer } & \multirow[t]{3}{*}{48} & Median sensory & 14 & 38 & 3.5 \\
\hline & & & Median motor & 7.6 & 55 & 3.7 \\
\hline & & & Ulnar sensory & 14 & 51 & 2.3 \\
\hline \multirow[t]{3}{*}{8} & \multirow{3}{*}{$\begin{array}{l}\text { Manual } \\
\text { manufacturer }\end{array}$} & 43 & Median sensory & 2 & 28 & 5.2 \\
\hline & & & Median motor & 8.8 & 53 & 4.7 \\
\hline & & & Ulnar sensory & 12 & 59 & 2.1 \\
\hline 9 & Housewife & 61 & Median sensory & 21 & 39 & 3.7 \\
\hline & & & Median motor & 6.5 & 52 & 3.8 \\
\hline & & & Ulnar sensory & 16 & 60 & 2.2 \\
\hline 10 & Housewife & 74 & Median sensory & 4.2 & 26.5 & 5.0 \\
\hline & & & Median motor & 4 & 48 & 3.9 \\
\hline & & & Ulnar sensory & 17 & 47 & 2.5 \\
\hline 11 & Cook & 48 & Median sensory & 4 & 67 & 2.3 \\
\hline & & & Median motor & 4.3 & 59 & 4.2 \\
\hline & & & Ulnar sensory & 22 & 60 & 2.0 \\
\hline 12 & Housewife & 65 & Median sensory & 4.6 & 23.3 & 4.8 \\
\hline & & & Median motor & 5.9 & 50 & 3.7 \\
\hline & & & Ulnar sensory & 14.2 & 42 & 2.2 \\
\hline 13 & Housewife & 53 & Median sensory & 2.5 & 22 & 5.0 \\
\hline & & & Median motor & 4.4 & 57 & 4.2 \\
\hline & & & Ulnar sensory & 16 & 55.8 & 2.4 \\
\hline 14 & Housewife & 66 & Median sensory & 2.6 & 19.3 & 5.7 \\
\hline & & & Median motor & 4.6 & 52 & 4.4 \\
\hline & & & Ulnar sensory & 14 & 56 & 2.0 \\
\hline 15 & Dressmaker & 55 & Median sensory & 2 & 21 & 5.2 \\
\hline & & & Median motor & 5 & 50 & 4.1 \\
\hline & & & Ulnar sensory & 16 & 95 & 3.0 \\
\hline
\end{tabular}

CTS = carpal tunnel syndrome. 


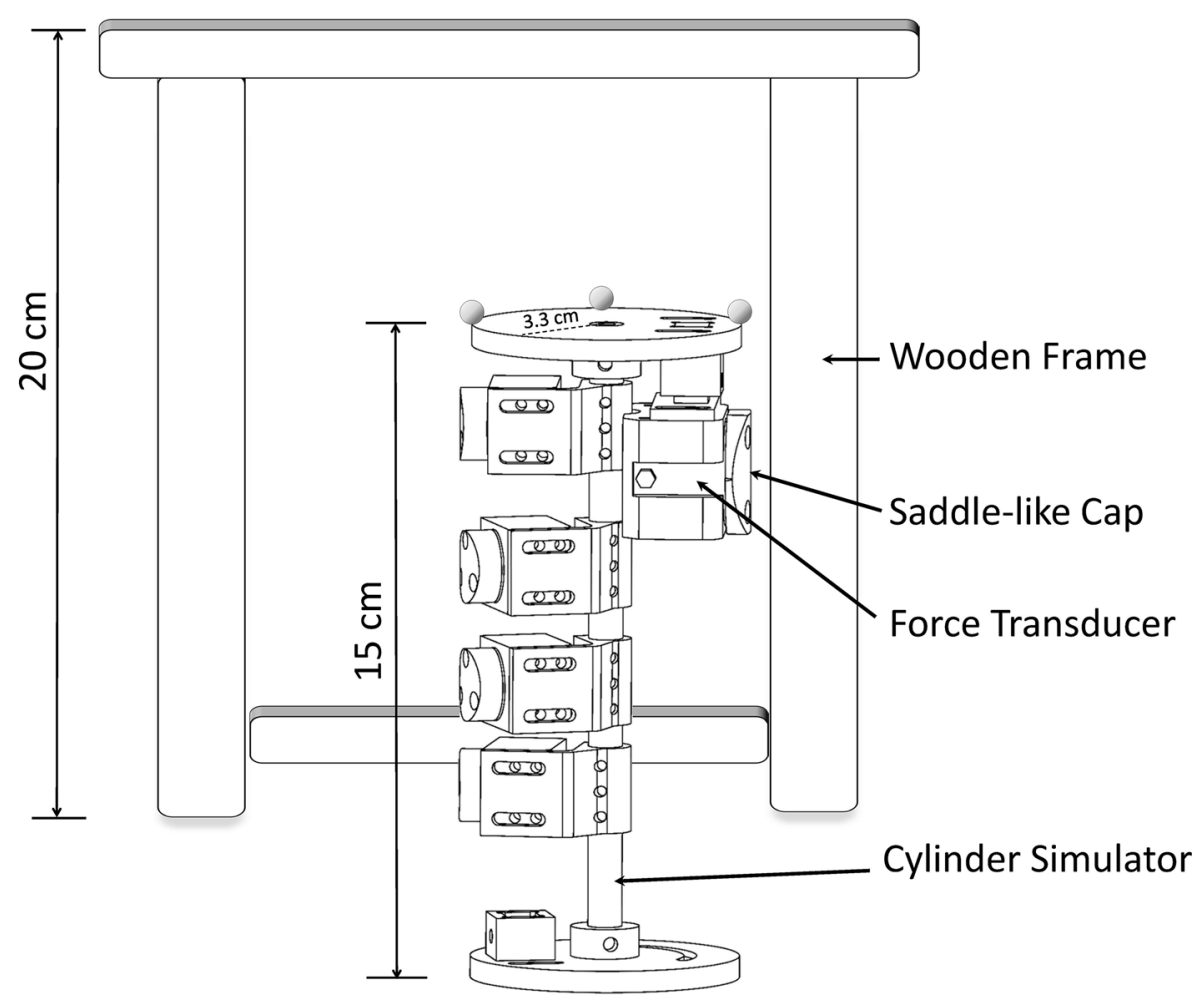

Fig. 1 The cylinder simulator apparatus (height, $15 \mathrm{~cm}$; weight, $390 \mathrm{~g}$ ) with five force transducers which were adjustable to natural grasping configuration, was used to record the applied forces of digits.

the table in front (Fig. 2). The simulator was located at the midline of the participant at a distance of her forearm length. Before data recording, the participants were asked to grasp the simulator in their usual way so that the positions of the transducers could be adjusted until each digit pad could comfortably contact the center of its respective transducer. The testing tasks were performed by using minimal force at the subject's self-selected speed, and the participants were allowed to familiarize themselves with the apparatus and tasks. Three successful trials were required, and a trial would be restarted if any errors occurred. The testing movement of the lift-hold-lower task was done with the following steps: grasping and lifting the simulator upward and vertically to the height of $20 \mathrm{~cm}$, then holding it in the air for at least 3 seconds, and finally lowering it to the original place (Fig. 3). The target height of $20 \mathrm{~cm}$ was guided by a wooden frame (Figs. 1 and 2). All participants underwent clinical sensory evaluations on the digits innervated by the median nerve, including the two-point discriminative test and the Semmes-Weinstein monofilaments test. There were no differences between the control subjects and CTS group regarding age (56 \pm 6 years [range, 47-65 years] and $53 \pm 11$ years [range, $35-74$ years], $\mathrm{p}=0.401)$, height $(157 \pm 5 \mathrm{~cm} \quad$ and $155 \pm 4 \mathrm{~cm}, \mathrm{p}=0.337)$, body weight $(56 \pm 7 \mathrm{~kg}$ and $60 \pm 11 \mathrm{~kg}, \mathrm{p}=0.190$ ) and hand size (palm length,
The movement of the simulator was represented by the three markers on the top. A wooden frame was used to guide the height of lifting.

$93 \pm 5 \mathrm{~mm}[95 \% \mathrm{CI}, 90-96 \mathrm{~mm}]$ and $90 \pm 10 \mathrm{~mm}[95 \%$ CI, 84-95 mm], $\mathrm{p}=0.281$; palm width, $76 \pm 3 \mathrm{~mm}[95 \%$ $\mathrm{CI}, 74-78 \mathrm{~mm}$ ] and $74 \pm 7 \mathrm{~mm}$ [95\% CI, 70-78 mm], $\mathrm{p}=0.281$ ). The digits innervated by the median nerve showed impaired sensory functions in the patients with CTS compared with the control subjects on the two-point discriminative test $(5 \pm 1 \mathrm{~mm}$ and $4 \pm 0.8 \mathrm{~mm}$, $\mathrm{p}<0.001 ; \quad 6 \pm 2 \mathrm{~mm}$ and $4 \pm 0.4 \mathrm{~mm}, \quad \mathrm{p}<0.001$; $6 \pm 1 \mathrm{~mm}$ and $4 \pm 1 \mathrm{~mm}, \mathrm{p}<0.001 ; 5 \pm 0.9 \mathrm{~mm}$ and $4 \pm 0.9 \mathrm{~mm}, \mathrm{p}<0.001$; for the thumb, index, middle and ring fingers, respectively) and Semmes-Weinstein monofilaments test $(0.49 \pm 0.58 \mathrm{~g}$ and $0.07 \pm 0.09 \mathrm{~g}$, $\mathrm{p}=0.009 ; 0.41 \pm 0.48 \mathrm{~g}$ and $0.06 \pm 0.10 \mathrm{~g}, \mathrm{p}=0.008$; $0.36 \pm 0.43 \mathrm{~g} \quad$ and $\quad 0.06 \pm 0.09 \mathrm{~g}, \quad \mathrm{p}=0.016$; $0.24 \pm 0.35 \mathrm{~g}$ and $0.04 \pm 0.03 \mathrm{~g}, \mathrm{p}=0.042$; for the thumb, index, middle, and ring fingers, respectively). However, the little finger of patients with CTS also showed the retarded response on the two-point discriminative test ( $5 \pm 0.8 \mathrm{~mm}$ versus $4 \pm 1 \mathrm{~mm}, \mathrm{p}=0.001$ ), but not in the Semmes-Weinstein monofilaments test with the numbers available $\quad(0.26 \pm 0.40 \mathrm{~g} \quad$ versus $\quad 0.06 \pm 0.09 \mathrm{~g}$, $\mathrm{p}=0.072$ ). The maximal strength of the evaluated hand also was measured based on the grasp of the tip pinch and three-jaw chuck pinch using a pinch gauge (PG-30; Pinsco, Inc, Santa Ana, CA, USA) and power grip using a hand dynamometer (Jamar $^{\circledR}$ Plus+; Patterson Medical, 

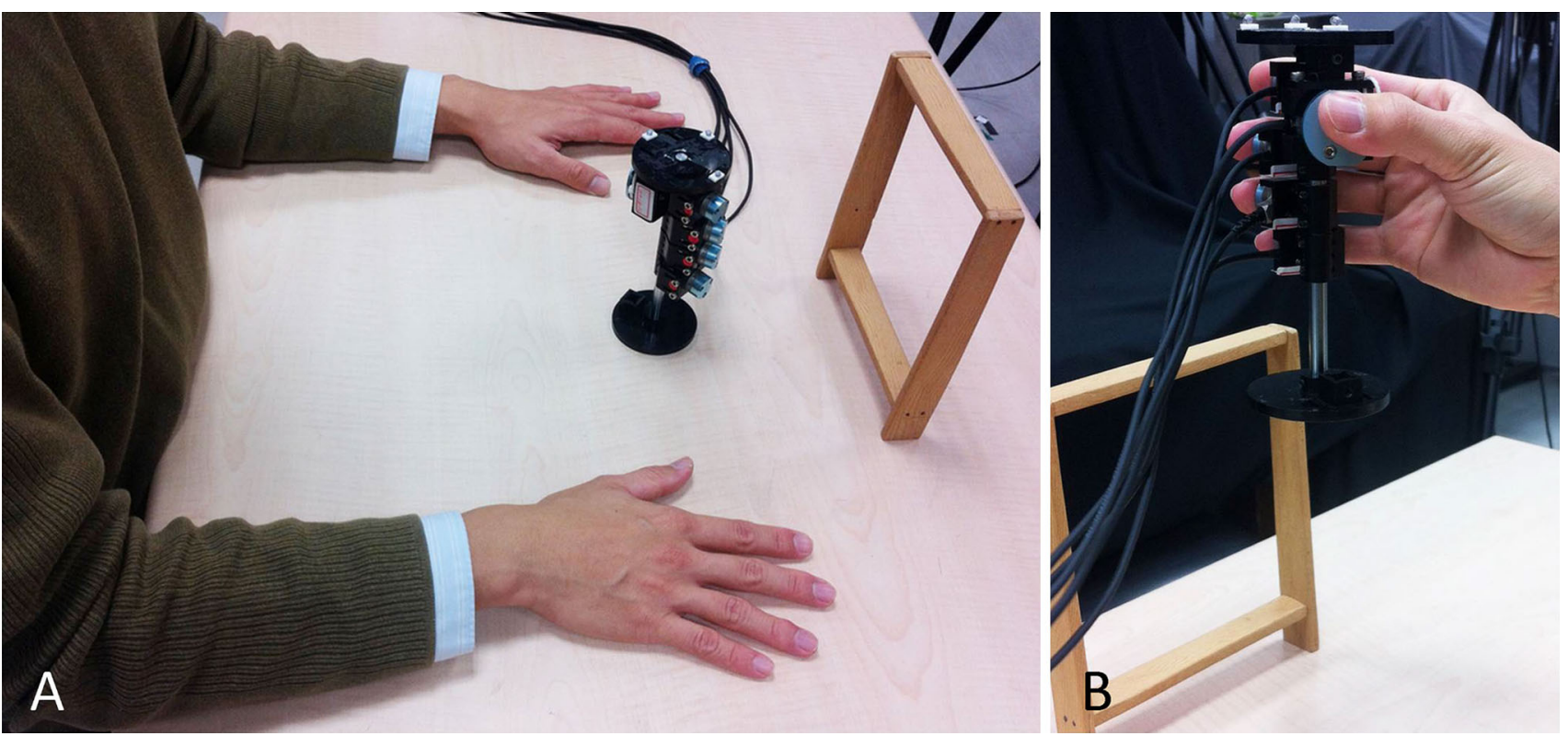

Fig. 2A-B (A) Each subject sat upright with the forearms resting on the table in front and the simulator was located at the midline at a distance of forearm length. (B) The lift-hold-lower task was

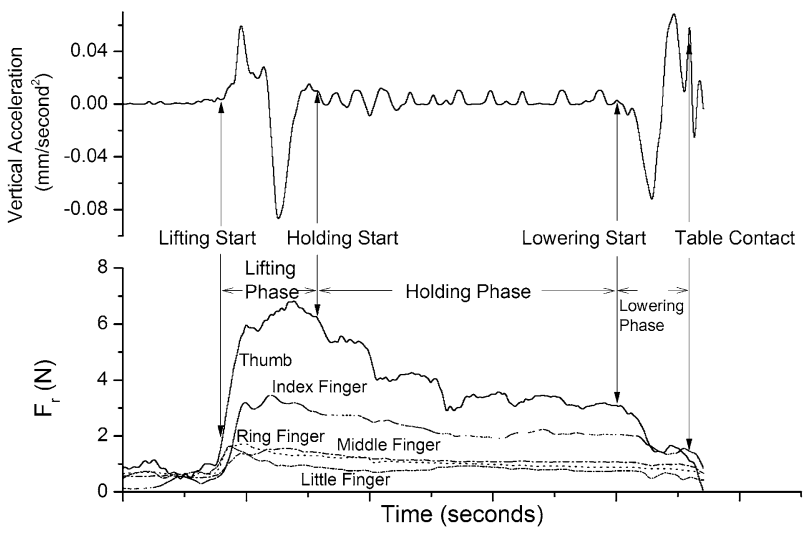

Fig. 3 The definitions of the four events (lifting start, holding start, lowering start, and table contact) and three phases (lifting, holding, and lowering phases) were based on the vertical acceleration during the lift-hold-lower task.

Warrenville, IL, USA). The patients with CTS had weaker maximal grip force than the control subjects $(14 \pm 6 \mathrm{~kg}$ and $23 \pm 5 \mathrm{~kg}, \mathrm{p}<0.001$ ), whereas there were no differences, with the numbers available, in the maximal force of tip pinch $(6 \pm 3 \mathrm{~kg}$ and $5 \pm 1 \mathrm{~kg}, \mathrm{p}=0.337)$ and threejaw chuck tests $(6 \pm 3 \mathrm{~kg}$ and $6 \pm 1 \mathrm{~kg}, \mathrm{p}=0.587)$.

\section{Data Analysis and Statistics}

According to the acceleration of the simulator in the superoinferior direction, calculated by differentiating the position data of the geometric centers of three markers performed by grasping and lifting the simulator upward and vertically to the height of $20 \mathrm{~cm}$, then holding it in the air for at least 3 seconds, and finally lowering it to the original place.

(Fig. 1), the movement sequences of the lift-hold-lower task can be determined by specific movement events (lifting start, holding start, lowering start, and table contact) and separated into two transient phases (lifting and lowering phases) and one steady phase (holding phase).

All the force data were filtered by a low-pass Butterworth filter (fourth order with a cutoff frequency of $10 \mathrm{~Hz}$ ) before further analysis. To compare the amplitude of applied $F_{\mathrm{r}}$ throughout the task between groups, the averaged digit $F_{r}$ in each group was obtained after resampling the raw digit $F_{r}$ of each trial to 100 points per phase. The mean value of $F_{r}$ at every resampling point in each group then was computed. The force correlations of the four thumb-finger pairs (thumb-index finger, thumb-middle finger, thumb-ring finger, and thumb-little finger) were analyzed throughout the task for each participant. To discover the changes in the correlation patterns between groups, the coefficients of force pairs were transformed through Fisher's Z-transformation to the normal distribution values for further computations. The force variability of each digit was evaluated by the root mean square value $\left(\mathrm{RMS}_{f v}\right)$ of the difference between the applied $\mathrm{F}_{\mathrm{r}}$ and its predicted value based on the fitting line by the first-order polynomial regression method during the holding phase.

The Pearson correlation coefficient was used to quantify the force correlation of thumb-finger pairs. The differences in the clinical evaluations and force parameters between the groups were measured by independent t-tests. In addition, one-way ANOVA was conducted to assess the effects 

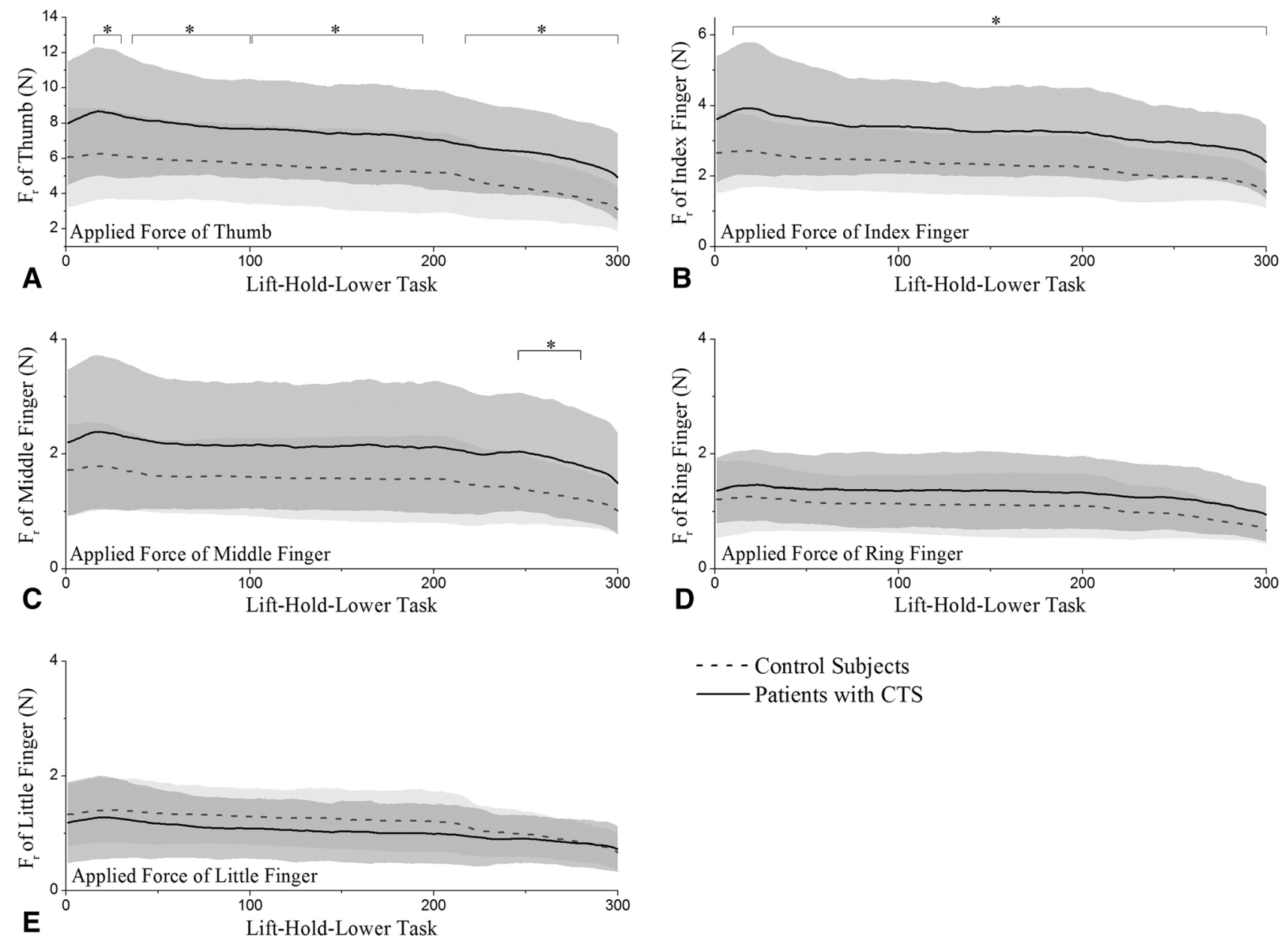

Fig. 4A-E The averaged digit $F_{r}$ for (A) the thumb, and the (B) index, (C) middle, (D) ring, and (E) little fingers throughout the lift-hold-lower task were obtained by resampling the data to 100 points per phase $\left(1^{\text {st }}-100^{\text {th }}\right.$ percentile, lifting phase; $101^{\text {st }}-200^{\text {th }}$ percentile, holding phase; $201^{\text {st }}-300^{\text {th }}$ percentile, lowering phase). The dashed line with light gray represents the values of the means and SDs of $F_{r}$ for the control subjects and the solid line with dark gray is

of various task phases on the patterns of force correlation and the post hoc test was performed using the least significant difference. The Pearson correlation coefficient also was used to find the relationships between the variability in force and levels of applied force in both groups. All the analytic processes were performed using MATLAB $^{\circledR}$ (MathWorks, Inc, Natick, MA, USA) and SPSS 17.0 (SPSS Inc, Chicago, IL, USA) software. The statistical significance was set at a probability less than 0.05 .

\section{Results}

The Applied $\mathrm{F}_{\mathrm{r}}$

The trace of each digit $\mathrm{F}_{\mathrm{r}}$ was generally not different with the numbers available between groups, but the statistical

for the CTS group. *Significant differences between the digit $\mathrm{F}_{\mathrm{r}}$ for the control subjects and CTS groups at specific data points: the $15^{\text {th }}$ to $30^{\text {th }}, 36^{\text {th }}$ to $100^{\text {th }}, 101^{\text {st }}$ to $194^{\text {th }}$, and $217^{\text {th }}$ to $300^{\text {th }}$ percentiles of the thumb $F_{r}$; the $10^{\text {th }}$ to $300^{\text {th }}$ percentile of the index finger $F_{r}$; and the $246^{\text {th }}$ to $280^{\text {th }}$ percentile of the middle finger $F_{r} \quad(p<0.05)$. $\mathrm{CTS}=$ carpal tunnel syndrome.

results indicated that the applied $\mathrm{F}_{\mathrm{r}}$ of the thumb and index finger among the patients with CTS were greater than those of the control subjects throughout most of the task (Fig. 4); mean $\mathrm{F}_{\mathrm{r}}$ across three phases (thumb: $7 \pm 0.8 \mathrm{~N}[95 \% \mathrm{CI}$, $7.2-7.4 \mathrm{~N}]$ and $5 \pm 0.8 \mathrm{~N} \quad[95 \% \quad \mathrm{CI}, \quad 5.1-5.3 \mathrm{~N}]$, $\mathrm{p}<0.001$; index finger: $3 \pm 0.3 \mathrm{~N}$ [95\% CI, 3.2-3.3 N] and $2 \pm 0.3 \mathrm{~N}$ [95\% CI, 2.2-2.3 N], p < 0.001). A larger $\mathrm{F}_{\mathrm{r}}$ of the middle finger for the patients with CTS also occurred during the last $1 / 2$ of the lowering phase (mean $\mathrm{F}_{\mathrm{r}}$ during lowering phase, $2 \pm 0.2 \mathrm{~N}$ [95\% CI, 1.9-2.0 N] and $1 \pm 0.1 \mathrm{~N}$ [95\% CI, 1.3-1.4 N], p < 0.001). There were no differences with the numbers available between the CTS group and control subjects regarding the $\mathrm{F}_{\mathrm{r}}$ of the ring finger (mean $\mathrm{F}_{\mathrm{r}}$ across three phases, $1.3 \pm 0.1 \mathrm{~N}[95 \% \mathrm{CI}$, $1.3-1.3 \mathrm{~N}]$ and $1.1 \pm 0.1 \mathrm{~N}$ [95\% CI, 1.1-1.1 N]) and little finger (mean $\mathrm{F}_{\mathrm{r}}$ across three phases, $1 \pm 0.1 \mathrm{~N}[95 \%$ CI, $1.0-1.0 \mathrm{~N}]$ and $1.2 \pm 0.2 \mathrm{~N}$ [95\% CI, 1.2-1.2 N]). 
Table 2. Means (SDs) of the correlation coefficients between the $F_{r}$ of the thumb and each of four fingers in three phases

\begin{tabular}{|c|c|c|c|c|}
\hline Phases & Thumb-index finger & Thumb-middle finger & Thumb-ring finger & Thumb-little finger \\
\hline \multicolumn{5}{|l|}{ Lifting } \\
\hline Control subjects & $0.90(0.12)$ & $0.82(0.16)$ & $0.85(0.15)^{\S}$ & $0.75(0.18)^{\bullet}$ \\
\hline Patients with CTS & $0.86(0.14)$ & $0.69(0.20)$ & $0.64(0.21)$ & $0.67(0.21)$ \\
\hline \multicolumn{5}{|l|}{ Holding } \\
\hline Control subjects & $0.77(0.18)$ & $0.59(0.22)^{*}$ & $0.45(0.25)^{\S, \|}$ & $0.75(0.18)^{* *}$ \\
\hline Patients with CTS & $0.73(0.19)^{\dagger}$ & $0.48(0.24)$ & $0.64(0.21)$ & $0.51(0.24)^{*}$ \\
\hline \multicolumn{5}{|l|}{ Lowering } \\
\hline Control subjects & $0.87(0.15)$ & $0.92(0.12)^{*}$ & $0.90(0.13)^{\|}$ & $0.90(0.13)^{\uparrow, * *}$ \\
\hline Patients with CTS & $0.89(0.14)^{\dagger}$ & $0.77(0.19)^{*}$ & $0.79(0.18)$ & $0.63(0.23)^{*}$ \\
\hline
\end{tabular}

CTS = carpal tunnel syndrome; *significantly lower coefficient in patients with CTS than control subjects for thumb-little finger during holding and lowering phases and thumb-middle finger during lowering phase; ${ }^{\dagger}$ significant differences between thumb-index finger correlation of patients with CTS during holding and lowering phases; ${ }^{*}$ significant differences between thumb-middle finger correlation of control subjects during holding and lowering phases; ${ }^{\S}$ significant differences between thumb-ring finger correlation of control subjects during lifting and holding phases; "significant differences between thumb-ring finger correlation of control subjects during holding and lowering phases; ${ }^{{ }^{\top}}$ significant differences between thumb-little finger correlation of control subjects during lifting and lowering phases; **significant differences between thumb-little finger correlation of control subjects during holding and lowering phases.

\section{The Force Correlations of Digit Pairs}

The CTS group showed smaller correlation coefficients of the thumb-finger pairs than the control subjects on the thumb-little finger during the holding phase $(0.5 \pm 0.2$ [95\% CI, 0.3-0.7] and $0.8 \pm 0.2$ [95\% CI, 0.6-0.9], $\mathrm{p}=0.023)$ and lowering phase $(0.6 \pm 0.2[95 \% \mathrm{CI}$, $0.3-0.8$ ] and $0.9 \pm 0.1$ [95\% CI, 0.8-1.0], $\mathrm{p}=0.010$ ) and the thumb-middle finger $(0.8 \pm 0.2$ [95\% CI, 0.6-0.9] and $0.9 \pm 0.1$ [95\% CI, 0.8-1.0], $\mathrm{p}=0.038$ ) during the lowering phase (Table 2). Regarding the effect of different phases of the task, the results indicated that the correlations of the thumb-middle finger $\left(\mathrm{F}_{2,12}=6.07, \mathrm{p}=0.005\right)$, thumb-ring finger $\left(\mathrm{F}_{2,12}=6.07, \mathrm{p}=0.002\right)$, and thumblittle finger $\left(\mathrm{F}_{2,12}=3.46, \mathrm{p}=0.041\right)$ in the control subjects and the thumb-index finger $\left(F_{2,12}=3.46, p=0.015\right)$ in the CTS group were associated with the demands made in each of the phases. The post hoc test by least significant difference revealed smaller coefficients at the holding phase than the lowering phase on the thumb-middle finger (holding, $0.6 \pm 0.2$ [95\% CI, 0.3-0.8]; lowering, $0.9 \pm 0.1$ [95\% CI, 0.8-1.0], $\mathrm{p}<0.001$ ), smaller at the holding phase than the lifting and lowering phases on the thumb-ring finger (lifting, $0.9 \pm 0.2$ [95\% CI, 0.7-0.9]; holding, $0.5 \pm 0.3$ [95\% CI, 0.1-0.7]; lowering, $0.9 \pm 0.1$ [95\% CI, $0.8-1.0] ; \mathrm{p}=0.007$ and $\mathrm{p}<0.001$ ), and larger at the lowering phase than the lifting and holding phases on the thumb-little finger (lifting, $0.8 \pm 0.2$ [95\% CI, 0.6-0.9]; holding, $0.8 \pm 0.2$ [95\% CI, 0.6-0.9]; lowering, $0.9 \pm 0.1$ [95\% CI, 0.6-0.9]; $\mathrm{p}=0.027$ and $\mathrm{p}=0.029$ ) in the control subjects. However, in the CTS group, only a weaker relationship of the thumb-index finger in the holding phase compared with that in the lowering phase was seen (holding, $0.7 \pm 0.2$ [95\% CI, 0.6-1.2]; lowering, $0.9 \pm 0.1$ [95\% CI, 0.8-0.9]; $\mathrm{p}=0.015$ ).

The Force Variability During the Holding Phase

The results showed that the $\mathrm{RMS}_{f v}$ of the thumb, index, middle, and ring fingers in the patients with CTS were larger than in the control subjects (thumb, $0.26 \pm 0.11 \mathrm{~N}$ $[95 \% \mathrm{CI}, \quad 0.20-0.32 \mathrm{~N}]$ and $0.19 \pm 0.06 \mathrm{~N}[95 \% \mathrm{CI}$, $0.16-0.22 \mathrm{~N}], \mathrm{p}=0.037$; index finger, $0.09 \pm 0.07 \mathrm{~N}$ $[95 \% \mathrm{CI}, \quad 0.05-0.13 \mathrm{~N}]$ and $0.05 \pm 0.03 \mathrm{~N}[95 \% \mathrm{CI}$, 0.04-0.07 N], $\mathrm{p}=0.040$; middle finger, $0.06 \pm 0.04 \mathrm{~N}$ [95\% CI, $0.04-0.08 \mathrm{~N}]$ and $0.03 \pm 0.01 \mathrm{~N}$ [95\% CI, $0.02-0.04 \mathrm{~N}], \mathrm{p}=0.014$; ring finger, $0.04 \pm 0.03 \mathrm{~N}[95 \%$ $\mathrm{CI}, \quad 0.02-0.06 \mathrm{~N}]$ and $0.02 \pm 0.01 \mathrm{~N} \quad[95 \% \quad \mathrm{CI}$, 0.02-0.02 N], $\mathrm{p}=0.008$ ), although no difference was observed regarding the little finger $(0.04 \pm 0.04 \mathrm{~N}[95 \%$ $\mathrm{CI}, \quad 0.02-0.06 \mathrm{~N}]$ and $0.03 \pm 0.02 \mathrm{~N} \quad[95 \%$ CI, $0.02-0.05 \mathrm{~N}], \mathrm{p}=0.544$ ) with the numbers available. Furthermore, in the patients with CTS, direct correlations between $\mathrm{RMS}_{f v}$ and the mean $\mathrm{F}_{\mathrm{r}}$ of the holding phase were found in the index $(\mathrm{r}=0.66, \mathrm{p}=0.007)$, middle $(\mathrm{r}=0.83, \mathrm{p}<0.001)$, and little $(\mathrm{r}=0.71, \mathrm{p}=0.003)$ fingers (Fig. 5). However, such relationships between $\mathrm{RMS}_{f v}$ and averaged $\mathrm{F}_{\mathrm{r}}$ were absent in the control subjects.

\section{Discussion}

Without intact sensory feedback from the median nerve distribution, the precision grasp function is limited to some extent in patients with CTS. The forces applied by patients 
with CTS therefore are excessive and unable to precisely meet the needs of the task. However, the ability to control digit forces in the functional grasping configuration has not been reported in very many studies [21, 23, 29, 42-45]. We therefore examined the deficiencies in digit force control during five-digit grasping in patients with CTS. We found that the patients grasped by higher digit force, weaker correlation, and higher variability on specific digits than the control subjects. This suggests the sensory impairment of CTS affected the coordination of digit forces during natural grasping, even though the minimal force and selfselected speed were requested to grasp the simulator for the simple task.

This study has some limitations regarding our finding on the ability to control digits. First, although impairments to sensory functions and force patterns may be associated with the duration of nerve irritation, the actual duration of CTS often is unknown by patients because it is a gradual process. Second, we did not quantify hand activities used in activities of daily living. More practice of dexterous manipulation may enhance the force control ability and strengthen the intrinsic muscles. Third, because of the high incidence of CTS in females, only female patients were recruited in this study. To simplify the problem caused by impaired sensory function, mild to moderate CTS was studied since severe CTS may affect motor function profoundly and the patient might be unable to perform the task completely. Therefore our results might not be able to be generalized to male patients or patients with severe CTS. Fourth, some study variables without differences between groups might have been caused by the small number of participants, such as the differences between groups for applied force and force correlation being noticed only during some phases. Finally, the poor response of the little finger to sensory evaluation was seen in some of the patients with CTS, although the patients with impaired ulnar nerve functions and with radiculopathy had been excluded. Paresthesia of the little finger in patients with CTS, which may be attributable to increased pressure in Guyon's canal transmitted from the high carpal tunnel pressure via the transverse ligament, has been seen in patients with mild CTS [5, 16-18]. Despite the smaller contribution from the little finger to the lift-hold-lower task we observed and as reported in a previous study [8], it may be worthwhile to investigate the effects on force control in patients with impaired sensation on little finger to further clarify the role of the little finger during five-digit grasping.

The patients with CTS exerted more $F_{r}$ of the thumb and index finger throughout the task, and on the middle finger during the lowering phase, than that seen in the control group. This is similar to previous observations that patients with CTS grasp objects with excessive force in various configurations $[1,29,39,42,45]$. This inefficiency of applied force is attributed to the impaired cutaneous sensation of the digits, because the pinch efficiency improved with recovery of sensory functions after carpal tunnel release [21]. However, it was difficult for the patients with CTS to grasp with five digits rather than pinching, because the former required coordination among five digits which included the intact digits and those affected by CTS [26, 44]. By assessing the relationship between applied force during grasping and the sensory status of each digit across patients and controls, only weak correlations between twopoint discrimination and applied force on the thumb $(\mathrm{r}=0.392, \mathrm{p}=0.032)$ and ring finger $(0.436, \mathrm{p}=0.016)$ were seen. Our assessment revealed that any alteration of each digit force will cause interdigit compensation during grasping by multiple digits, rather than intradigit behavior. We also observed this altered coordination in patients with CTS in maximal strength evaluations. The patients showed decreased power grip strength compared with the control subjects while the strengths of the tip and three-jaw chuck pinch were preserved. The decreased strength of the power grip may be attributable to the ability of patients with CTS to do synchronous maximal exertion either from all of the digits, including the intact and involved digits, or the intrinsic and extrinsic muscles [15, 23]. Furthermore, the index and middle fingers and the thumb contributed more than the other digits to the total grasping force during the natural grasping configuration [8]. The patients with CTS adopted compensatory strategies mainly by augmenting the forces of these three most important digits to perform daily tasks, which may lead to the cumulative overloading to the musculotendons and to secondary injuries. It is common to see the development of trigger digits in patients with idiopathic CTS especially after carpal tunnel release [19, 20, 35]. Therefore, the pattern of applied digit force with CTS should be kept in mind for the clinician to educate patients and for the researcher to examine the possible pathomechanics.

Although the force synergy of the thumb and fingers during multidigit grasping obeys the simple patterns of pair relationships, the patterns vary depending on the tasks performed and the related grasping configurations and impairments of the hand [8, 24, 36]. The decreased correlations seen in the patients with CTS may be because the $\mathrm{F}_{\mathrm{r}}$ of the thumb and opposite finger were adjusted in a nonsynchronous manner, which was observed as the mismatched tendency in the changes in force. From a neurophysiologic perspective, the electromyographic coherence of pair muscles, which varies across digits and implies that neural inputs from the central controller drive the engaged digits by coordinating the related digital muscles, may be altered in specific digits in patients with CTS [12, 32]. In addition, our patients with CTS showed few alterations of pair correlations with respect to the phase 

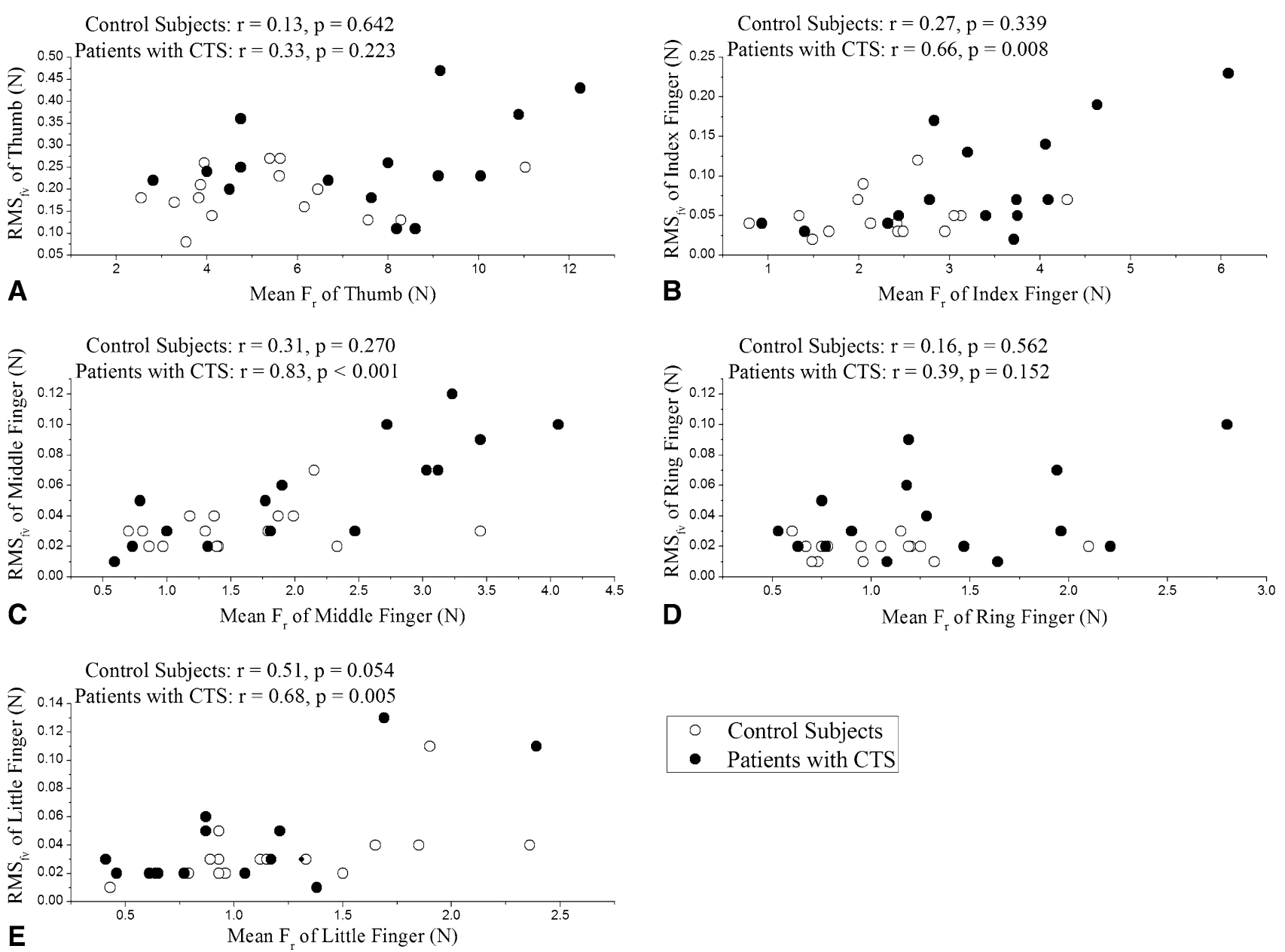

Fig. 5A-E The relationships between force variability $\left(\mathrm{RMS}_{f v}\right)$ and mean applied force $\left(\mathrm{F}_{\mathrm{r}}\right)$ during the holding phase are shown for the (A) thumb, and (B) index, (C) middle, (D) ring, and (E) little fingers.

changes. The task-dependent patterns of five-digit grasping have been examined from the perspectives of kinematics and kinetics, and these are coordinated according to the different requirements of the tasks such as the end position or mass of an object [4, 10, 11, 21, 30,33]. During lifting and lowering, more emphasis regarding control of the digits' forces should be placed on acceleration and deceleration of objects. Therefore, strong corresponding relationships of the finger-thumb pairs may have been required to move the simulator and prevent it from overshooting the target height during lifting or impacting the table during the lowering phase in the current study. The patients with CTS had an increased thumb-index finger correlation only during the lowering phase, which may be because the central controller minimized the degree of freedom by augmenting the relative roles of the thumb and index finger [25]. Furthermore, reorganization of the brain structures was found to correlate with the nerve conduction velocity in patients with CTS, and this was thought to be a

The significant correlations were found only in the patients with CTS on the $(\mathbf{B})$ index, $(\mathbf{C})$ middle and $(\mathbf{E})$ little fingers, but no correlation was seen in the control subjects. CTS $=$ carpal tunnel syndrome.

secondary adaption to the peripheral nerve impairments [31]. However, more research is needed to link the relationships between the motor performance of the distal hand and central neural activities to verify the related control mechanism. The decreased force correlation with less adjustment to the changes of task demand in patients with CTS may retard the performance of an advanced precise task, such as with a hand tool used during surgery.

In the current study, the predominant force variability of the first four digits (thumb, index, middle, and ring fingers) in patients with CTS may be attributable to their insufficient awareness of the amount of applied forces required owing to the impaired sensory functions. Furthermore, we found that the variability increased along with the applied force in the index, middle, and little fingers of the patients with CTS. Although this was observed only in three digits, this finding is similar to the results of previous studies which reported that the variability of pinch force correlated with the force level in healthy subjects [14, 32]. Because 
the lift-hold-lower task was performed using the participants' self-selected minimal forces, and without the assistive guide of an applied force, the variability represented the force adjustments needed to achieve efficient exertion and to maintain the equilibrium of the simulator. If considering the force level during the holding phase by normalizing the sum of $F_{r}$ from the five digits to the maximal grip force, holding the simulator was more demanding for the patients with CTS than for the control subjects. The reason why no trend of correlation was noticed in control subjects may be because the applied force and associated force variability of each digit in this group were controlled in a smaller range than that seen in the patients with CTS [3]. Additional studies are required to investigate the control mechanism of force variability across ranges of force levels during five-digit grasping. The measurement of force variability established in our study can be used to quantify the stability control of digit force and applied in other populations.

We found that higher digit force was associated with weaker correlation and higher variability in specific digits in patients with CTS than in the control subjects. Although it was known that the sensory impairment disturbed the digit force application, the applied force during natural grasping can represent how the patients grasped during daily activities. Future studies might consider following these findings to determine whether the altered pattern changes after carpal tunnel release, and to examine the relationship between trigger digit and applied digit forces in patients after carpal tunnel release. The presented findings may help us appreciate the altered pattern of grasping force in daily function and provide the clinician with information that may help design a rehabilitation program for patients with similar carpal tunnel syndrome.

Acknowledgments We thank You-Hua Su MS, Ching-Hung Teng MS and Yi-Hsien Liu MS, Department of Biomedical Engineering, National Cheng Kung University, for assistance with data collection and analysis.

\section{References}

1. Afifi M, Santello M, Johnston JA. Effects of carpal tunnel syndrome on adaptation of multi-digit forces to object texture. Clin Neurophysiol. 2012;123:2281-2290.

2. Amirjani N, Ashworth NL, Olson JL, Morhart M, Chan KM. Validity and reliability of the Purdue Pegboard Test in carpal tunnel syndrome. Muscle Nerve. 2011;43:171-177.

3. Bland JM, Altman DG. Correlation in restricted ranges of data. BMJ. 2011;342:d556.

4. Budgeon MK, Latash ML, Zatsiorsky VM. Digit force adjustments during finger addition/removal in multi-digit prehension. Exp Brain Res. 2008;189:345-359.

5. Caliandro P, La Torre G, Aprile I, Pazzaglia C, Commodari I, Tonali P, Padua L. Distribution of paresthesias in carpal tunnel syndrome reflects the degree of nerve damage at wrist. Clin Neurophysiol. 2006;117:228-231.

6. Chang MH GL, Hsieh PF, Huang SY. A randomised clinical trial of oral steroids in the treatment of carpal tunnel syndrome: a long term follow up. $J$ Neurol Neurosurg Psychiatry. 2002;73:710-714.

7. Chang SH, Francisco GE, Zhou P, Rymer WZ, Li S. Spasticity, weakness, force variability, and sustained spontaneous motor unit discharges of resting spastic-paretic biceps brachii muscles in chronic stroke. Muscle Nerve. 2013;48:85-92.

8. Chen PT, Lin CJ, Jou IM, Chieh HF, Su FC, Kuo LC. One digit interruption: the altered force patterns during functionally cylindrical grasping tasks in patients with trigger digits. PloS One. 2013;8:e83632.

9. Chiu HY, Hsu HY, Kuo LC, Chang JH, Su FC. Functional sensibility assessment. Part I: develop a reliable apparatus to assess momentary pinch force control. $J$ Orthop Res. 2009;27:1116-1121.

10. Cohen RG, Rosenbaum DA. Where grasps are made reveals how grasps are planned: generation and recall of motor plans. Exp Brain Res. 2004;157:486-495.

11. Craje C, Lukos JR, Ansuini C, Gordon AM, Santello M. The effects of task and content on digit placement on a bottle. Exp Brain Res. 2011;212:119-124.

12. Danna-Dos Santos A, Poston B, Jesunathadas M, Bobich LR, Hamm TM, Santello M. Influence of fatigue on hand muscle coordination and EMG-EMG coherence during three-digit grasping. J Neurophysiol. 2010;104:3576-3587.

13. Endo H, Kawahara K. Relationship between hand stability and the $10-\mathrm{Hz}$ physiological tremor during various manual tasks. Ergonomics. 2010;53:491-501.

14. Endo H, Kawahara K. Gender differences in hand stability of normal young people assessed at low force levels. Ergonomics. 2011;54:273-281.

15. Geere J, Chester R, Kale S, Jerosch-Herold C. Power grip, pinch grip, manual muscle testing or thenar atrophy: which should be assessed as a motor outcome after carpal tunnel decompression? A systematic review. BMC Musculoskelet Disord. 2007;8:114.

16. Ginanneschi F, Filippou G, Reale F, Scarselli C, Galeazzi M, Rossi A. Ultrasonographic and functional changes of the ulnar nerve at Guyon's canal after carpal tunnel release. Clin Neurophysiol. 2010;121:208-213.

17. Ginanneschi F, Milani P, Mondelli M, Dominici F, Biasella A, Rossi A. Ulnar sensory nerve impairment at the wrist in carpal tunnel syndrome. Muscle Nerve. 2008;37:183-189.

18. Ginanneschi F, Milani P, Rossi A. Anomalies of ulnar nerve conduction in different carpal tunnel syndrome stages. Muscle Nerve. 2008;38:1155-1160.

19. Grandizio LC, Beck JD, Rutter MR, Graham J, Klena JC. The incidence of trigger digit after carpal tunnel release in diabetic and nondiabetic patients. $J$ Hand Surg Am. 2014;39:280-285.

20. Hayashi M, Uchiyama S, Toriumi H, Nakagawa H, Kamimura M, Miyasaka T. Carpal tunnel syndrome and development of trigger digit. J Clin Neurosci. 2005;12:39-41.

21. Hsu HY, Kuo LC, Chiu HY, Jou IM, Su FC. Functional sensibility assessment. Part II: Effects of sensory improvement on precise pinch force modulation after transverse carpal tunnel release. J Orthop Res. 2009;27:1534-1539.

22. Jenkins PJ, Srikantharajah D, Duckworth AD, Watts AC, McEachan JE. Carpal tunnel syndrome: the association with occupation at a population level. J Hand Surg Eur Vol. 2013;38:67-72.

23. Kuo LC, Hsu HM, Wu PT, Lin SC, Hsu HY, Jou IM. Impact of distal median neuropathy on handwriting performance for patients with carpal tunnel syndrome in office and administrative support occupations. J Occup Rehabil. 2014;24:332-343. 
24. Li ZM. Inter-digit co-ordination and object-digit interaction when holding an object with five digits. Ergonomics. 2002;45:425-440.

25. Li ZM, Latash ML, Newell KM, Zatsiorsky VM. Motor redundancy during maximal voluntary contraction in four-finger tasks. Exp Brain Res. 1998;122:71-78.

26. Li ZM, Latash ML, Zatsiorsky VM. Force sharing among fingers as a model of the redundancy problem. Exp Brain Res. 1998;119:276-286.

27. Lodha N, Naik SK, Coombes SA, Cauraugh JH. Force control and degree of motor impairments in chronic stroke. Clin Neurophysiol. 2010;121:1952-1961.

28. Louie DL, Earp BE, Collins JE, Losina E, Katz JN, Black EM, Simmons BP, Blazar PE. Outcomes of open carpal tunnel release at a minimum of ten years. $J$ Bone Joint Surg Am. 2013;95:1067-1073.

29. Lowe BD, Freivalds A. Effect of carpal tunnel syndrome on grip force coordination on hand tools. Ergonomics. 1999;42:550-564.

30. Lukos J, Ansuini C, Santello M. Choice of contact points during multidigit grasping: effect of predictability of object center of mass location. J Neurosci. 2007;27:3894-3903.

31. Maeda Y, Kettner N, Sheehan J, Kim J, Cina S, Malatesta C, Gerber J, McManus C, Mezzacappa P, Morse LR, Audette J, Napadow V. Altered brain morphometry in carpal tunnel syndrome is associated with median nerve pathology. Neuroimage Clin. 2013;2:313-319.

32. Poston B, Danna-Dos Santos A, Jesunathadas M, Hamm TM, Santello M. Force-independent distribution of correlated neural inputs to hand muscles during three-digit grasping. J Neurophysiol. 2010;104:1141-1154.

33. Rearick MP, Casares A, Santello M. Task-dependent modulation of multi-digit force coordination patterns. J Neurophysiol. 2003;89:1317-1326.

34. Ross MA, Kimura J. AAEM case report \#2: the carpal tunnel syndrome. Muscle Nerve. 1995;18:567-573.
35. Rottgers SA, Lewis D, Wollstein RA. Concomitant presentation of carpal tunnel syndrome and trigger finger. $J$ Brachial Plex Periph Nerve Inj. 2009;4:13.

36. Santello M, Soechting JF. Force synergies for multifingered grasping. Exp Brain Res. 2000;133:457-467.

37. Serazin C, Ha C, Bodin J, Imbernon E, Roquelaure Y. Employment and occupational outcomes of workers with musculoskeletal pain in a French region. Occup Environ Med. 2013;70:143-148.

38. Sosnoff JJ, Newell KM. Are age-related increases in force variability due to decrements in strength? Exp Brain Res. 2006;174:86-94.

39. Thonnard J, Saels P, Van den Bergh P, Lejeune T. Effects of chronic median nerve compression at the wrist on sensation and manual skills. Exp Brain Res. 1999;128:61-64.

40. Tubiana R, Thomine JM, Mackin E. Examination of the Hand and Wrist. London, Martin Dunitz; 1998.

41. Yang CP, Wang NH, Li TC, Hsieh CL, Chang HH, Hwang KL, Ko WS, Chang MH. A randomized clinical trial of acupuncture versus oral steroids for carpal tunnel syndrome: a long-term follow-up. J Pain. 2011;12:272-279.

42. Yen WJ, Kuo YL, Kuo LC, Chen SM, Kuan TS, Hsu HY. Precision pinch performance in patients with sensory deficits of the median nerve at the carpal tunnel. Motor Control. 2014;18:29-43.

43. Zhang W, Johnston JA, Ross MA, Coakley BJ, Gleason EA, Dueck AC, Santello M. Effects of carpal tunnel syndrome on adaptation of multi-digit forces to object mass distribution for whole-hand manipulation. J Neuroeng Rehabil. 2012;9:83.

44. Zhang W, Johnston JA, Ross MA, Sanniec K, Gleason EA, Dueck AC, Santello M. Effects of carpal tunnel syndrome on dexterous manipulation are grip type-dependent. PloS One. 2013;8:e53751

45. Zhang W, Johnston JA, Ross MA, Smith AA, Coakley BJ, Gleason EA, Dueck AC, Santello M. Effects of carpal tunnel syndrome on adaptation of multi-digit forces to object weight for whole-hand manipulation. PloS One. 2011;6:e27715. 